\title{
Cabimento da Arbitragem nos Contratos Administrativos
}

\author{
Carlos Ari Sundfeld' \\ Jacintho Arruda Câmara ${ }^{2}$
}

\section{Introdução}

O tema do presente estudo é dos mais atuais. Com o incremento da arbitragem no direito brasileiro, discute-se, com interesse prático cada vez maior, a possibilidade de se aplicar a entes estatais esse modelo de resolução de conflitos.

A tendência legislativa, acompanhada pela própria prática da Administração Pública quando celebra seus contratos, tem sido a de buscar a aplicação dessa fórmula privada como mecanismo viável para se pôr termo a disputas de interesse.

No entanto, mesmo sem qualquer restrição específica presente na legislação, alguns ainda consideram que as entidades estatais não poderiam aderir a um procedimento arbitral. A origem de todo o questionamento é basicamente uma: considerar que os interesses tutelados pela Administração, em decorrência do princípio da indisponibilidade do interesse público, não se coadunariam com esse sistema não estatal de jurisdição.

Entendemos que a previsão de arbitragem envolvendo a Administração é perfeitamente legítima.

1 Professor Doutor da Faculdade e do Programa de Pós-Graduaçāo em Direito da Pontificia Universidade Católica de São Paulo. Professor da Escola de Direito de São Paulo da Fundação Getulio Vargas e Coordenador de sua Especialização em Direito Administrativo. Doutor e Mestre em Direito pela PUC/SP. Presidente da Sociedade Brasileira de Direito Público.

2 Professor de Direito Administrativo da Faculdade de Direito da PUC/SP. Mestre e Doutor em Direito pela PUC/SP. 
Para fundamentar nosso posicionamento, dividimos a exposição em dois tópicos básicos. No inicial descreveremos as principais objeções lançadas à adoção do procedimento arbitral por entidades estatais. Em seguida, apontaremos os fundamentos que nos levam a concluir pela possibilidade de aplicação de juízo arbitral em contratos firmados por entes estatais. Por fim, apontaremos o critério de julgamento próprio a arbitragens das quais façam parte entidades administrativas.

\section{Argumentos contrários à arbitragem}

Como já foi mencionado na introdução, existe um argumento recorrente contra a aplicação da arbitragem por entidades estatais. Trata-se de um verdadeiro lugar-comum. Apegando-se ao fato de a arbitragem se restringir a causas que envolvam "direitos disponíveis", foi cunhado o raciocínio segundo o qual todo litígio envolvendo a Administração Pública (direta ou indireta) deixaria de atender a esse requisito. A razão apontada estaria no princípio geral de direito administrativo da indisponibilidade do interesse público pelo administrador. Por essa linha de pensamento, todo e qualquer direito do qual seja titular uma entidade integrante da Administração seria indisponível e, por isso, insuscetível de ser discutido em procedimento arbitral.

Outro argumento empregado contra a adoção desse mecanismo pela Administração o refuta por considerá-lo espécie de transação a respeito do cumprimento da lei. Ao aderir à arbitragem, a Administraçâo estaria, inexoravelmente, abrindo mão de parte de seus direitos ou da obediência à lei, comportamento que, por força do princípio da legalidade estrita, seria incompatível com sua figura. Em resumo, por não poder transigir com o cumprimento da lei, a Administração supostamente estaria impedida de levar seus litígios a juízo arbitral.

A arbitragem também seria inaplicável a entes estatais por, supostamente, afastar do Judiciário o exame das matérias que fossem por ela tratadas. Seguindo essa premissa, tal efeito seria incompatível com o regime jurídico aplicável aos entes estatais, que permite o questionamento dos atos por eles produzidos por intermédio de diversos instrumentos processuais, como a ação popular (que legitima qualquer cidadão a questionar judicialmente atos lesivos ao erário) e a ação civil pública (instrumento à disposição do Ministério Público, para a defesa de interesses difusos e coletivos).

A ausência de previsão expressa, na Lei de Licitações e Contratos da Administração Pública (Lei 8.666/93), do sistema de arbitragem como mecanismo de solução extrajudicial de conflitos é mais um argumento contrário ao uso dessa ferramenta por entes estatais. Mais uma vez invocando o princípio da legalidade estrita, sustenta-se que a ausência de norma legal que autorize expressamente a 
utilização desse instrumento o tornaria inacessível à Administração Pública. ${ }^{3} \mathrm{~A}$ Lei 8.666/93 também vedaria a instituição de arbitragem, por prever, em seu art. $55, \S 2^{\circ}$, como cláusula obrigatória, a fixação do foro da sede da Administração para dirimir qualquer questão contratual. Essa previsão de foro impediria tacitamente que a Administração aderisse ao sistema de arbitragem.

Há ainda objeções específicas, que atingem a arbitragem que tome por objeto um determinado tema, como, por exemplo, a prestação de serviços públicos. Por envolver a prestação de serviço público, estaria desatendido o requisito da disponibilidade do direito.

Defende-se também que, sempre que o contrato no qual se prevê a arbitragem tenha sido alvo de impugnação judicial autônoma, incidiria um óbice intransponível ao prosseguimento da arbitragem. Por essa linha, a discussão judicial dos contratos (numa ação popular, por exemplo) teria o condão de inviabilizar a solução do litígio por meio de arbitragem.

São esses, em resumo, os argumentos lançados em desfavor da arbitragem. Como já adiantamos, não consideramos que eles sejam procedentes. Passaremos, a seguir, a demonstrar por que, apesar dessas impugnações, não vislumbramos impedimento jurídico à realização de arbitragem que tenha como objeto a discussão de contratos administrativos.

\section{Possibilidade do juízo arbitral envolvendo a Administração Pública}

\section{I Arbitragem e indisponibilidade do interesse público}

Quando se fala em arbitragem envolvendo entidade integrante da Administração Pública, a primeira questão a enfrentar diz respeito ao suposto obstáculo decorrente da aplicação do princípio da indisponibilidade do interesse público. Como já foi referido no tópico anterior, para alguns, o princípio constituiria um limite intransponivel à adoção do procedimento arbitral pela Administração Pública. A linha de argumentação desenvolvida para fundamentar essa ideia é bastante simplista: como a arbitragem só teria cabimento sobre direitos disponíveis, ela estaria invariavelmente afastada dos direitos relativos à Administração, uma vez que estes seriam, todos, por força do aludido princípio, indisponíveis.

O raciocínio é linear, fácil de ser assimilado e, talvez por isso, acabe exercendo um efeito sedutor em alguns intérpretes. No entanto, a aplicação do princípio da indisponibilidade do interesse público ao presente tema mostra-se completamente fora de contexto e, consequentemente, inadequada.

3 O argumento, naturalmente, nāo se aplica aos contratos de concessāo de serviço público, sejam os tradicionais, sejam os caracterizados como parcerias público-privadas, visto que, em tais casos, há previsāo legislativa expressa amparando a utilizaçāo de arbitragem (art. 23-A da Lei 8.987/95 e art. 11, III, da Lei 11.073/04). 
O princípio da indisponibilidade do interesse público não estabelece propriamente um dever ou proibição. Não configura o que a doutrina costuma denominar de princípio-regra. ${ }^{4}$ Trata-se de um principio-valor, que encarna uma ideia comum a todo o sistema normativo que compõe o Direito Administrativo. Sua função não é a de prescrever condutas, mas sim apontar um traço característico daquele conjunto de normas, contribuindo para sua compreensão e posterior interpretação.

O princípio da indisponibilidade do interesse público, nessa linha, reflete uma importante característica do Direito Administrativo: a de que as autoridades não agem por vontade própria, como se dispusessem livremente dos interesses que guardam. Elas lidam com coisa alheia, pública, sobre a qual não dispõem. Noutros termos, o princípio em tela reforça a noção segundo a qual o administrador deve obediência à lei, na medida em que atua na gestão de interesses cujo titular (a coletividade) se expressa mediante decisões do Legislativo. ${ }^{5}$

Não foi esse o sentido que a legislação empregou, ao estabelecer que a arbitragem só se destina a "dirimir litígios relativos a direitos patrimoniais disponíveis". Com essa demarcação, a Lei de Arbitragem afastou de seu âmbito de aplicação apenas os temas que não admitissem contratação pelas partes. Numa palavra, a lei limitou a aplicação do procedimento arbitral às questões referentes a direito (ou interesse) passivel de contratação. ${ }^{6}$ Para evitar confusão terminológica - que propicie um falso embate em face do princípio da indisponibilidade do interesse público -, passaremos a designar este requisito como a existência de um direito negociável.

4 Como é o caso do princípio da legalidade, que impõe à Administração o dever de agir mediante prévia autorização legislativa.

5 Confiram-se, nesse sentido, as palavras do professor Celso Antônio Bandeira de Mello, um dos doutrinadores que mais divulgaram esse princípio no Direito brasileiro: "A indisponibilidade dos interesses públicos significa que, sendo interesses qualificados como próprios da coletividade - internos ao setor público -, não se encontram à livre disposição de quem quer que seja, por inapropriáveis. $O$ próprio órgão administrativo que os representa não tem disponibilidade sobre eles, no sentido de que lhe incumbe apenas curá-los - o que é também um dever - na estrita conformidade do que predispuser a intentio legis. [...] Em suma, o necessário - parece-nos - é encarecer que na administração os bens e os interesses não se acham entregues à livre disposição da vontade do administrador. Antes, para este, coloca-se a obrigação, o dever de curá-los nos termos da finalidade a que estão adstritos. É a ordem legal que dispõe sobre ela" (Curso de Direito Administrativo, 18. ed., Malheiros Editores, São Paulo, 2005, p. 64-65).

6 A confusão conceitual em referência é desfeita pela liçāo do Prof. Eros Grau: "Assim, é evidente que quando se afirma que a arbitragem se presta a 'dirimir litígios relativos a direitos patrimoniais disponíveis' isso nāo significa que não possa, a Administração, socorrer-se dessa via visando ao mesmo fim. Pois não há qualquer correlação entre disponibilidade ou indisponibilidade de direitos patrimoniais e disponibilidade ou indisponibilidade do interesse público. Dispor de direitos patrimoniais é transferi-los a terceiros. Disponíveis são os direitos patrimoniais que podem ser alienados. A Administração, para realização do interesse público, pratica atos, da mais variada ordem, dispondo de determinados direitos patrimoniais, ainda que não possa fazê-lo em relação a outros deles. Por exemplo, não pode dispor dos direitos patrimoniais que detém sobre os bens públicos de uso comum. Mas é certo que inúmeras vezes deve dispor de direitos patrimoniais, sem que com isso esteja a dispor do interesse público, porque a realização deste último é alcançada mediante a disposição daqueles. [...] Daí porque, sempre que puder contratar, o que importa disponibilidade de direitos patrimoniais, poderá a Administração, sem que isso importe disposição do interesse público, convencionar cláusula de arbitragem" (Arbitragem e Contrato Administrativo, RTDP 32/20). 
A casuística do direito privado torna mais fácil a percepção do que a lei pretendeu afastar de sua abrangência. $O$ direito a alimentos, por exemplo, constitui, indiscutivelmente, um tema de caráter patrimonial, mas que não é passível de contratação pelos envolvidos. Isto é, não se pode contratualmente decidir como eles serão prestados, ou mesmo deles dispor, sem pronunciamento judicial. Por isso, não se pode resolver conflitos dessa natureza por intermédio de arbitragem, mesmo que os interessados estivessem dispostos a assim proceder. Direitos não patrimoniais, como o direito à liberdade, à vida, à saúde, entre outros, também são insuscetíveis de discussão em procedimento arbitral.

A mesma lógica se aplica quando se tratar de direitos e interesses de entidade estatal. Aqueles interesses (direitos) que podem ser contratados também poderão ser objeto de cláusula de arbitragem. Quando firma um contrato qualquer, a Administração está assumindo um determinado ônus, com a perspectiva de receber uma contrapartida estipulada. Nesse caso, algum direito de caráter patrimonial daquela entidade está sendo negociado, por isso há de ser considerado, para efeito de aplicação da lei de arbitragem, um direito disponível, ou seja, um direito negociável.

É tradicional no Direito Administrativo a distinção entre atos de império e atos de gestão. ${ }^{7}$ Os primeiros dizem respeito a matérias inerentes ao Estado, que corresponderiam ao plexo de interesses "indisponíveis" do Poder Público. Os outros envolvem os atos de mera administração. São atos despidos de prerrogativas especiais, cujo objetivo é fixar relações jurídicas normais (de direito comum) entre a Administração e outras pessoas jurídicas. Aproveitando desta vetusta classificaçāo, seria possível afirmar que a intenção da Lei de Arbitragem foi reservar para seu escopo as matérias objeto de atos de gestão. Estariam excluídos de sua abrangência aqueles temas que são objeto de atos de império.

\subsection{Arbitragem e transação}

É importante ressaltar que, ao submeter uma discussão à arbitragem, as partes não estão abrindo mão de seus direitos ou mesmo transigindo (isto é, aceitando perder parte do seu direito). Ao se valerem da arbitragem, as partes na verdade escolhem um juizo privado para pôr termo ao litígio. A arbitragem apontará quem tem razão na disputa. Cada parte terá oportunidade de expor seus argumentos, defendê-los, produzir prova, enfim, terá oportunidade de influenciar na decisão a ser tomada, de modo a proteger seus interesses. Nāo se confunde com um mero acordo, com a aceitação passiva da redução de seu patrimônio ou com algo semelhante. É improcedente, portanto, o argumento segundo o qual a Administração

; Nas palavras de Celso Antônio Bandeira de Mello, atos de império são "os que a Administraçāo praticava no gozo de prerrogativas de autoridade", como, por exemplo, "a ordem de interdição de um estabelecimento". Atos de gestão seriam "os que a Administração praticava sem o uso de poderes comandantes". Como seria o caso da "venda de um bem" ou "os relativos à gestão de um serviço público" (Curso de direito administrativo, p. 397). 
não poderia aderir à arbitragem por não poder "abrir mão" de seus direitos, ou "transigir" na aplicação da Lei. O argumento é falacioso, pois a arbitragem não implica quaisquer dessas práticas.

\subsection{Arbitragem e autorização legislativa}

Outra suposta barreira, de caráter geral, à participação de entes estatais em arbitragens seria a ausência de autorização legislativa. Pelo fato de não existir previsão expressa na Lei 8.666/93, nem na Lei de Arbitragem, a respeito da utilização do procedimento arbitral por entes estatais, haveria uma proibição tácita desta prática. Agrega-se a esse raciocínio a previsão contida na Lei 8.666/93 (art. $55, \$ 2^{\circ}$ ), que obriga, nos contratos celebrados pela Administração, a inclusão de cláusula estipulando como foro competente para solução de qualquer litígio o da sede da Administração. A Lei 8.666/93, com esse dispositivo, teria determinado que a solução de qualquer litígio seria judicial, o que excluiria a arbitragem.

Esses argumentos provam demais. ${ }^{8}$ A legislação sobre contratações públicas não é exaustiva quanto à instituição de modelos contratuais que podem ser empregados pela Administraçāo. Muito pelo contrário. As contrataçōes públicas foram disciplinadas de maneira genérica, prevendo-se cláusulas gerais que deveriam constar em qualquer tipo de pacto, mas sem excluir outras previsões. Qualquer modelo contratual previsto em lei, desde que não contrarie as previsões especificas da Lei 8.666/93, pode ser empregado pelas entidades integrantes da Administração Pública.

Assim ocorre com a arbitragem. Trata-se de um sistema de jurisdição privada, a ser aplicado mediante acordo entre as partes envolvidas. É, portanto, um tipo de contrato (ou de cláusula) que está à disposição das pessoas em geral, inclusive aquelas integrantes da Administração Pública. Na Lei de Arbitragem não há referência expressa aos entes estatais, como também não há em relação a qualquer outra espécie de pessoa. A lei foi dirigida a todas as pessoas, genericamente. Não houve qualquer discriminação em relação a pessoas físicas ou jurídicas, a pessoas de direito público ou de direito privado, a pessoas estatais ou não estatais. A única

8 Referida tese é assim refutada por Gustavo Binenbojm: "Em primeiro lugar, a ausência de uma autorização legal explícita e específica nāo pode ser considerada per se como óbice à pactuaçāo da cláusula compromissória em contratos da Administração. Tal exigência parte da premissa - equivocada - de que a cláusula de arbitragem constitui um ato de disposição da Administração Pública, o que é equivocado. A autorização legal (geral e orçamentária) para a realização de despesas pela Administração, mediante celebraçāo de contratos com particulares, importa, a fortiori, a autorização para que o administrador faça uso de todos os meios negociais disponíveis para a melhor consecução dos interesses da coletividade. Assim, v. g., pode a Administraçāo Pública proceder ao acertamento direto de seus conflitos com os particulares, o que não ofende à legalidade. Por igual razão, pode a Administração pactuar a realização de procedimento arbitral, como o meio mais eficiente de soluçāo de suas controvérsias com particulares. Trata-se de um poder implícito ao dever de bem administrar o patrimônio público e promover o interesse público aquele de obrigar-se à soluçāo arbitral de conflitos" (As Parcerias Público-Privadas (PPPS) e a Constituição, RDA 241/173). 
exigência feita foi a de que a pessoa seja capaz de contratar. Sendo pessoa com capacidade jurídica para firmar contrato, ela poderá também se valer da arbitragem. Essa é a regra imposta por lei. Como não se discute a capacidade de contratação das entidades estatais, não há como negar que tais figuras estão incluídas entre as pessoas aptas a fazer uso do procedimento arbitral.

A previsão de uma cláusula elegendo o foro da sede da Administração como competente para a solução de litígios não afasta, de modo algum, a possibilidade de arbitragem em contratos administrativos. A previsão legal de foro, por óbvio, diz respeito apenas ao local de processamento de demandas judiciais. A lei restringiu apenas a liberdade de as partes contratantes estabelecerem o local onde se processará as demandas judiciais envolvendo o contrato. Em suma, a Lei 8.666/93 definiu que em contratos da Administração não cabe a previsāo de outro foro, que não o de sua sede. Porém, tal restrição não impede que os conflitos sejam decididos sem recurso ao Judiciário. Ela não impede, por exemplo, a celebração de acordos entre Administração e empresa contratada, para resolver possíveis conflitos. ${ }^{9}$ Do mesmo modo, a fixação legal de foro não afeta a eventual previsão de arbitragem para solucionar determinados conflitos surgidos no âmbito dos contratos firmados pela Administração. A arbitragem, como procedimento extrajudicial, não afeta a regra que estabelece o foro que deve ser previsto nos contratos administrativos. A lei determina apenas que, se houver conflito judicial, o foro deve ser o da sede da Administração.

\subsection{Arbitragem e acesso à jurisdição}

Existe ainda a alegação de que a arbitragem impediria o exame judicial das questões nela decididas, contrariando, com isso, dispositivos constitucionais que asseguram o controle judicial das práticas administrativas. Mais uma vez se está diante de um argumento improcedente. ${ }^{10}$ Não só a própria Lei de Arbitragem prevê a possibilidade de revisão judicial das decisões tomadas com nulidade, ${ }^{11}$ como também é possível que pessoas alheias ao compromisso arbitral venham a levar a juízo as questōes que foram nele abrangidas. Deveras, a arbitragem só vincula as partes que a pactuaram, ${ }^{12}$ sendo perfeitamente factível que outros legitimados (como o Ministério Público, associações de proteção a interesses difusos,

\footnotetext{
Mostra disso é a previsão de rescisāo amigável do contrato, contida na própria Lei 8.666/93 (art. 79, II).

10 Também refutam a tese Adilson Dallari, Arbitragem na Concessão de Serviço Público, em Boletim de Direito Administrativo, nº 9, Editora NDJ, São Paulo, 1996, p. 575, e Gustavo Binenbojm, obra citada, p. 175.

11 É o que dispōe seu art. 33: "A parte interessada poderá pleitear ao órgão do Poder Judiciário competente a decretaçāo da nulidade da sentença arbitral, nos casos previstos nesta Lei."

12 Art. 31 da Lei de Arbitragem: "A sentença arbitral produz, entre as partes e seus sucessores, os mesmos efeitos da sentença proferida pelos órgāos do Poder Judiciário e, sendo condenatória, constitui título executivo."
} 
cidadãos em geral) proponham açōes judiciais que questionem tais matérias (via ação civil pública ou ação popular).

\subsection{Arbitragem e impugnação judicial do contrato por terceiros}

Há quem sustente que o surgimento de impugnação judicial, por terceiros (autor popular, Ministério Público), quanto a algum contrato ou ato da Administração, cria óbice ao início ou prosseguimento de arbitragem sobre questōes relativas a esses contratos ou atos.

A superveniência de ação popular ou ação civil pública questionando a validade do contrato não é barreira para a instituição ou prosseguimento de arbitragem. A decisão judicial, muito embora possa, em tese, chegar a resultado distinto daquele alcançado na arbitragem, não tem o condão de transformar em indisponiveis os direitos nela tratados. O contrato, mesmo sendo objeto de questionamento judicial, continuará versando sobre direitos patrimoniais, negociáveis e, portanto, passíveis de exame em procedimento arbitral.

A Lei só determina a suspensão da arbitragem se surgir demanda judicial que traga à tona direito indisponível do qual venha a depender o julgamento arbitral. ${ }^{13} \mathrm{O}$ ajuizamento de ação sobre questões objeto do procedimento arbitral não altera a natureza dos direitos e interesses envolvidos. Se, porventura, a sentença judicial modificar algumas das decisōes tomadas na arbitragem, ocorrerá pura e simples substituição, da ordem proferida pelo juízo arbitral, por aquela editada judicialmente. ${ }^{14}$ Trata-se de contingência inafastável das controvérsias submetidas à arbitragem, uma vez que, nos termos da própria Lei de Arbitragem, uma sentença arbitral pode vir a ser anulada judicialmente, caso descumpra qualquer dos requisitos impostos à sua validade.

A arbitragem não é prejudicada pelo surgimento de demanda judicial sobre matéria correlata. A Lei de Arbitragem foi bem clara (art. 25): a suspensão só será necessária se a discussão envolver matéria de outra natureza (vier a tratar de direito indisponível, vale dizer, inegociável).

Nesses casos, como em qualquer outro, o resultado da sentença arbitral vinculará imediatamente às partes envolvidas, constituindo título executivo (art.

13 É o que dispōe o art. 25 da Lei de Arbitragem. Confira-se: "Sobrevindo no curso da arbitragem controvérsia acerca de direitos indisponíveis e verificando-se que de sua existência, ou não, dependerá o julgamento, o árbitro ou o tribunal arbitral remeterá as partes à autoridade competente do Poder Judiciário, suspendendo o procedimento arbitral."

14 Adilson Dallari, em estudo pioneiro, já apontava a perfeita convivência da decisão arbitral com os meios processuais especiais de defesa do patrimônio público: “Além disso, cabe destacar que o compromisso arbitral vincula apenas as partes contratantes, não se estendendo a terceiros, que, julgando-se prejudicados, sempre poderão recorrer à via judicial para a defesa de seus direitos e interesses. Em se tratando de contratos administrativos, onde sempre estão presentes interesses públicos, é absolutamente certo que nāo se poderá impedir a eventual propositura de Ação Popular ou de Ação Civil Pública, conforme o caso" (Arbitragem na Concessāo de Serviço Público, em Boletim de Direito Administrativo, $\mathrm{n}^{\circ}$ 9, Editora NDJ, Sāo Paulo, 1996, p. 575). 
31 da Lei de Arbitragem). A pendência de uma discussão judicial sobre matéria abrangida nessa decisão não afasta, por si só, a eficácia do pronunciamento arbitral. Até que sobrevenha decisão judicial em sentido contrário, o resultado da arbitragem prevalecerá, podendo inclusive ser objeto de execução judicial.

\subsection{Arbitragem sobre temas relacionados a serviços públicos}

Outro argumento levantado para impugnar a arbitragem envolve especificamente seu emprego em matéria afeta à prestação de serviço público. Sempre que o contrato envolvesse tal objeto, a avença não poderia se submeter ao procedimento arbitral. $\mathrm{O}$ argumento recai sobre $o$ já debatido princípio da indisponibilidade do interesse público. A arbitragem, reservada a direitos disponiveis, não seria aplicável a um contrato que versasse sobre serviço público.

Como se sabe, a titularidade do serviço público é irrenunciável. Este aspecto de seu regime jurídico está, realmente, fora do plexo de direitos negociáveis do Estado. Isso, porém, não significa dizer que tudo o mais que seja relacionado à prestação de serviços públicos não possa vir a ser objeto de contratação e, consequentemente, de compromisso arbitral.

Ninguém discute que a prestação de serviços públicos pode ser objeto de delegação a particulares, o que se faz mediante contratação. Logo, os direitos oriundos da exploração do referido serviço por terceiros são, indiscutivelmente, passiveis de negociação. Preços, condiçōes de pagamento, cronograma de investimento, financiamentos, enfim, tudo o que estiver relacionado à exploração econômica do serviço pode ser objeto de contratação e, nesta condição, ter seus conflitos dirimidos por arbitragem, se as partes assim pactuarem.

As condições de exploração são objeto de negociação desde um primeiro momento, quando o Poder Concedente delega o serviço do qual é titular para ser explorado por terceiros. As condiçōes econômicas de prestação do serviço são determinadas contratualmente entre o Poder Concedente e as empresas. Depois, no relacionamento de tais empresas com outros agentes do mercado, mais uma vez, o que se tem é a livre disposição sobre condiçōes econômicas. Nesses casos, não há qualquer tratativa sobre questōes de império, ou seja, sobre temas insuscetíveis de negociação. As partes envolvidas definem, fazendo uso de seu respectivo poder de autotutela, quais as condições econômicas do relacionamento. A duração do contrato, a remuneração do contratado e as condiçōes de pagamento, multas pecuniárias e, se assim dispuserem, a sujeição do contrato à arbitragem são exemplos de temas que, embora digam respeito à prestação de um serviço público, podem ser perfeitamente objeto de negociação entre as partes envolvidas. Trata-se do que, na terminologia empregada na Lei de Arbitragem, é denominado de direito disponivel, isto é, direito negociável, passível de estipulação em contrato e, consequentemente, de ser objeto de procedimento arbitral. 
A sujeição desse tipo de pacto a uma decisão arbitral não interfere minimamente em questões de império (fora do comércio) relativas ao serviço público. Deveras, nenhum aspecto da titularidade do serviço é posto em xeque com a sujeição desses contratos a um juízo arbitral.

\section{Critério de julgamento a ser empregado na arbitragem}

Como se vê, não há princípio ou regra jurídica que proíba, de modo geral, a adoção da arbitragem pela Administração Pública. Isso, porém, não significa dizer que, sobre todo e qualquer assunto envolvendo interesses da Administração, seja possível aplicar esse sistema de solução de conflitos ou mesmo que ele seja aplicável sem qualquer adaptação ou cuidado especial. Não é isso que se está afirmando.

É imprescindível estabelecer limites à aplicação da Lei de Arbitragem às disputas envolvendo a Administração Pública.

Uma condição para a aplicação do procedimento arbitral em litígios envolvendo a Administração Pública refere-se ao critério de julgamento. A legislação prevê que a arbitragem tanto pode ser de direito como de equidade (art. $2^{\circ}$ da Lei de Arbitragem). Essa variação, todavia, não é aplicável aos procedimentos que envolvam a Administração Pública. Por força do princípio da legalidade, a Administração só pode se submeter a uma decisão que seja tomada com base em critérios rigorosamente jurídicos, oriundos de normas postas formalmente (em lei, regulamento, contrato ou ato administrativo). A decisão por equidade é construida com base em critérios subjetivos, levando em conta a noção de justiça e de equilíbrio que o julgador venha a adotar. Embora seja um fundamento válido em decisōes entre particulares (inclusive para fundamentar sentenças judiciais, como expressamente prevê a Lei de Introdução ao Código Civil), esse critério não se presta para temas envolvendo interesses de entes estatais, pois estes, por definição, não prescindem de disciplina em normas de direito (princípio da legalidade).

\section{Referências}

BANDEIRA DE MELLO, Celso Antônio. Curso de direito administrativo, 18. ed. São Paulo: Malheiros, 2005.

BINENBOJM, Gustavo. As Parcerias Público-Privadas (PPPS) e a Constituição. Revista de Direito Administrativo, nº 241, Rio de Janeiro: Renovar e Fundação Getulio Vargas, p. 159-175, jul./set. 2005.

DALLARI, Adilson. Arbitragem na Concessāo de Serviço Público. Boletim de Direito Administrativo, nº 9, São Paulo: NDJ, 1996. p. 571-575.

GRAU, Eros Roberto. Arbitragem e Contrato Administrativo. Revista Trimestral de Direito Público", nº 32, São Paulo: Malheiros, 2000. p. 14-20. 